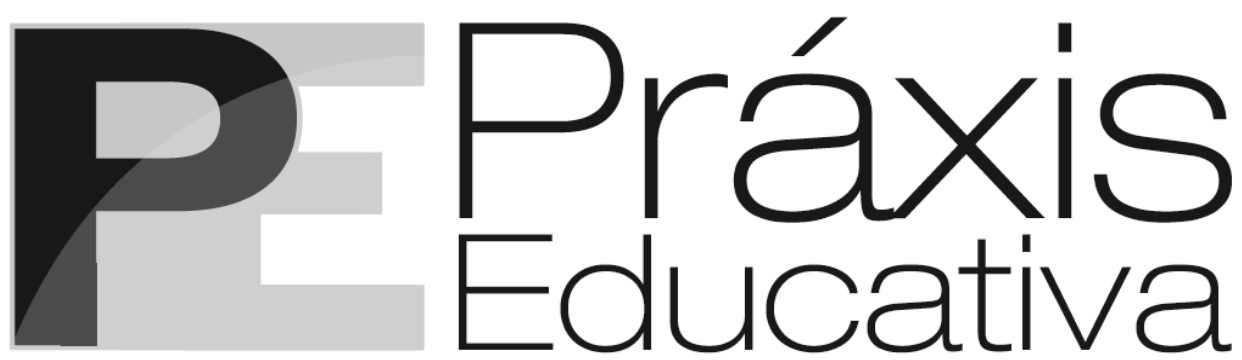

ISSN 1809-4031

elSSN 1809-4309

http://dx.doi.org/10.5212/PraxEduc.v.14n3.018

\title{
E quando a experiência vira campo? Reflexões a partir da observação participante nas ocupações secundaristas
}

\author{
And what about the experience turning into field? \\ Reflections from participant observation in secondary school occupations
}

\author{
¿Y cuándo la experiencia se convierte en campo? \\ Reflexiones a partir de la observación participante en las ocupaciones \\ secundarias
}

Carolina Simões Pacheco*
Ana Luisa Fayet Sallas

Resumo: Este trabalho é resultado do campo de pesquisa que orientou a dissertação de Mestrado, intitulada Ocupar e resistir: as ocupações das escolas públicas como parte do ciclo atual de mobilização juvenil no Brasil..** $\mathrm{O}$ relato foi organizado com base em excertos do trabalho de campo e tem como objetivo tratar dessa "entrada" da pesquisadora "no campo". Baseia-se na experiência da pesquisadora como participante que apoiava o movimento de ocupações e que, posteriormente, tornou-se tema de estudo. A óptica de análise da presente pesquisa pode ser descrita como a "participação observante", em uma referência direta a Wacquant (2002) e tem como objetivo abordar o tema a partir da metodologia qualitativa, como uma construção significativa em que o corpo constitui parte importante no desenvolvimento do campo de pesquisa.

Palavras-chave: Juventude. Movimentos sociais. Trabalho de campo.

\begin{abstract}
This work is the result of the research field that guided the Master's thesis entitled Ocupar e resistir: as ocupações das escolas públicas como parte do ciclo atual de mobilização juvenil no Brasil (Occupy and resist: the occupations of public schools as part of the current cycle of youth mobilization in Brazil). The report was organized based on excerpts from field work and aims to address this "entry" of the researcher "in the field". It is based on the researcher's experience as a participant who supported the movement of occupations and who subsequently became a study topic. The analysis of the present research can be described as "observant participation", in a direct reference to Wacquant (2002) and aims to approach the theme from the qualitative methodology, as a significant construction in which the body constitutes an important part in the development of the research field.

Keywords: Youth. Social movements. Fieldwork.

\footnotetext{
* Doutoranda do Programa de Pós-Graduação em Sociologia na Universidade Federal do Paraná. Bolsista da Coordenação de Aperfeiçoamento de Pessoal de Nível Superior (CAPES). E-mail: <carolsp9@gmail.com>. ORCID: https://orcid.org/0000-0003-3722-7914

** Professora do Programa de Pós-Graduação em Sociologia da Universidade Federal do Paraná (UFPR). E-mail: <analuisasallas@gmail.com>. ORCID: https://orcid.org/0000-0001-9928-6771

*** Pesquisa defendida em 2018 (PACHECO, 2018) e orientada pela Prof ${ }^{a}$ Dra. Ana Luisa Fayet Sallas.
}

Práxis Educativa, Ponta Grossa, v. 14, n. 3, p. 1121-1137, set./dez. 2019 Disponível em: <http://www.revistas2.uepg.br/index.php/praxiseducativa> 
E quando a experiência vira campo? Reflexões a partir da observação participante nas ocupações...

Resumen: Este trabajo es resultado del campo de investigación que orientó la disertación de maestría, titulada Ocupary resistir: las ocupaciones de las escuelas públicas como parte del ciclo actual de movilización juvenil en Brasil. El relato fue organizado con base en extractos del trabajo de campo y tiene como objetivo tratar de esta "entrada" de la investigadora "en el campo". Se basa en la experiencia de la investigadora como participante que apoyaba el movimiento de ocupaciones y que, posteriormente, se convirtió en tema de estudio. La óptica de análisis de la presente investigación puede ser descrita como la "participación observante", en referencia directa a Wacquant (2002) y tiene como objetivo abordar el tema a partir de la metodología cualitativa, como una construcción significativa en la que el cuerpo constituye una parte importante en el desarrollo del campo de investigación.

Palabras clave: Juventud. Movimientos sociales. Trabajo de campo.

\section{O trabalho de campo no C. E. Pedro Macedo}

Quando entrei ${ }^{1}$ no Mestrado, em 2016, era militante de um movimento social chamado Levante Popular da Juventude e construí a ocupação de uma escola secundarista, como apoiadora do movimento. Depois dessa experiência, no processo de elaboração da pesquisa e com a orientação da Profa. Dra. Ana Luisa Fayet Sallas, fiz, desse momento "vivido sociologicamente construído" (WACQUANT, 2002, p. 15), meu trabalho de campo, que teve caráter de participação observante, como veremos adiante (WACQUANT, 2002). No Programa de Pós-Graduação em Sociologia da Universidade Federal do Paraná, inseri-me, posteriormente, a um grupo de pesquisa intitulado "Sentidos e sentimentos das/nas ocupações", coordenado pela Profa. Dra. Simone Meucci. Nele, realizamos entrevistas com ocupantes de outros colégios, dentre outras atividades importantes para a decorrência desta pesquisa.

O trabalho de campo que embasa este relato foi realizado entre outubro e novembro de 2016, na ocupação do Colégio Pedro Macedo, em Curitiba. A minha militância foi condição que me possibilitou vivenciar a ocupação "por dentro", e, por isso, o trabalho de campo é fonte primária de minha pesquisa. A metodologia de pesquisa de meu Mestrado foi, assim, qualitativa. Participei da ocupação e, depois, voltei-me a essa experiência como temática a ser estudada. $\mathrm{O}$ campo é fruto de minhas memórias pós ocupações e, por isso, a ordem cronológica foi mantida, a fim de conduzir minha escrita.

É importante salientar, ainda nesta introdução, que a experiência emerge neste trabalho não somente como o ponto de partida para o campo, mas também como eixo importante que articula os sentidos atribuídos pelos ocupantes à ação política, em que partem de um sentimento negativo em relação à escola que, no processo de ocupação, é transformado por elas/es e positivado, à medida que se apropriam da escola como um território (SANTOS, 2005) onde novas formas de organização e sociabilidade são vividas. Referenciamo-nos, assim, na conceituação de Thompson (1981) sobre a experiência:

Exploramos, tanto na teoria como na prática, os conceitos de junção (como "necessidade", "classe" e "determinação"), pelos quais, através do termo ausente, "experiência", a estrutura é transmutada em processo, e o sujeito é reinserido na história. Ampliamos muito o conceito de classe, que os historiadores da tradição marxista empregam comumente - de maneira deliberada e não por uma "inocência" teórica - com uma flexibilidade e indeterminação desautorizadas tanto pelo marxismo como pela sociologia ortodoxa. (THOMPSON, 1981, p. 188).

\footnotetext{
${ }^{1}$ Pedimos licença para, neste artigo, por tratar-se de um relato de experiência de uma das autoras, Carolina Simões Pacheco, entrecruzar a primeira pessoa do singular com a primeira do plural.
}

Práxis Educativa, Ponta Grossa, v. 14, n. 3, p. 1121-1137, set./dez. 2019 Disponível em: <http://www.revistas2.uepg.br/index.php/praxiseducativa $>$ 
A experiência emerge, dessa forma, como o processo que confere sentido à pesquisa e à escola, uma vez que é a forma com que a própria pesquisadora e os estudantes se percebem no lugar em que estão inseridos, sua relação com seus pares e agem sobre eles. Segundo Thompson (1981, p. 189), a experiência pode ser compreendida como a "genética de todo processo histórico", por ser ela que insere os sujeitos nesse processo, confere sentidos específicos em meio ao compartilhamento deste e, ainda, exerce pressão sobre o conjunto.

\section{As ocupações das escolas públicas de 2016}

No dia 3 de outubro de 2016, estudantes secundaristas do Colégio Arnaldo Jansen, de São José dos Pinhais, ocuparam o colégio contra a proposta de Medida Provisória 746 (MP 746) de Reforma do Ensino Médio, proposta pelo Governo Federal ${ }^{2}$. São José dos Pinhais é uma cidade na região metropolitana de Curitiba, mas acreditamos que é importante começarmos com este apontamento: as ocupações aconteceram, em primeiro lugar, em colégios periféricos. Esse ponto é importante porque ressalta um aspecto apontado por Oscar Aguilera Ruiz (2014) em relação às mobilizações juvenis, que dizem respeito à "ordem" com que protestos acontecem. Os atos considerados "tradicionais", em geral, acontecem no centro e se estendem para as periferias. Os atos juvenis, no entanto, subvertem essa ordem, por tratar-se de processos políticos mobilizados de forma distinta, como veremos adiante. Destacamos, assim, que as ocupações começaram na periferia, ou em uma cidade da região metropolitana de Curitiba, e, depois, se estenderam para os colégios centrais.

Nesse mesmo dia, estudantes de diversas escolas de Curitiba e outras cidades da Região Metropolitana fizeram protestos contra a MP 746 e contra a PEC 241(55) ${ }^{3}$. As palavras de ordem eram, assim, "contra a MP 746", "contra a PEC 241" e "Fora Temer". ${ }^{4}$ Para além dos estudantes secundaristas, diversos setores da sociedade civil manifestaram-se. As críticas colocaram-se, de forma geral, em relação ao financiamento para a educação e ao caráter facultativo de determinadas disciplinas. A crítica dos estudantes à MP 746 e à PEC 241 (55) trata, ainda, da maneira, considerada intransigente, com que a proposta foi apresentada pelo Governo, pois não houve consulta aos estudantes, reafirmando o sentimento descrito por eles de invisibilização em relação às demandas educacionais. Assim, eles não foram reconhecidos (HONNETH, 2003) como atores relevantes, ou, como dizem, não lhes deram voz:

Nos dias que se seguiram, foi difícil contabilizar o número de ocupações novas que surgiram. Os estudantes criaram uma página no Facebook chamada "Ocupa Paraná", que foi uma ferramenta de articulação das ocupações, para divulgar informações sobre os colégios recentemente

\footnotetext{
2 A Medida Provisória 746 foi aprovada em 2017 e versa sobre a reforma do Ensino Médio. Os principais pontos abordados são a reformulação curricular, em que o currículo passa a ser organizado por eixos formativos que devem ser escolhidos pelos estudantes a partir do segundo ano. A oferta dos eixos, no entanto, fica a critério das escolas, que não precisam ofertar todos. Além disso, define a abertura de cursos técnicos nas escolas sem previsão orçamentária para ampliação de infraestrutura, bem como a contratação de profissionais para estas áreas sem formação em licenciatura, justificada pelo "notório saber". A MP 746 estabelece ainda, como objetivo central, a ampliação do ensino integral, divergindo das metas nacionais prioritárias estabelecidas até então pelas Conferências Nacionais de Educação e pelo Plano Nacional de Educação, de universalização do Ensino Médio.

3 A Proposta de Emenda Constitucional 241, que tramitou posteriormente no Senado Federal como PEC 55 e foi aprovada em 2017, estabelece um teto de investimentos públicos em setores como a educação, a saúde e a assistência social, com a justificativa de contingenciamento por conta da crise econômica no Brasil. Com a PEC 55, podemos afirmar que será impossível atingir a meta do Plano Nacional de Educação, de 10\% do PIB brasileiro investidos na educação, até 2024 .

4 As ocupações das escolas no Paraná podem ser consideradas a primeira grande manifestação em oposição ao governo de Michel Temer após o processo de impeachment da Presidenta Dilma Rousseff.
}

Práxis Educativa, Ponta Grossa, v. 14, n. 3, p. 1121-1137, set./dez. 2019 Disponível em: <http://www.revistas2.uepg.br/index.php/praxiseducativa> 
E quando a experiência vira campo? Reflexões a partir da observação participante nas ocupações...

ocupados, sobre as atividades culturais e artísticas realizadas nas ocupações, bem como listas de alimentos e de materiais de higiene para doações. As hashtags "\#Ocupa Tudo" e "\#Ocupar e Resistir" inundaram as redes sociais ${ }^{5}$. Foi possível, dessa forma, evidenciar a agilidade com que as escolas foram ocupadas, rompendo com a blindagem das grandes mídias que não comentavam a quantidade de ocupações. Os estudantes ainda puderam compartilhar informações sobre os métodos utilizados para dividir as tarefas, as frases de protestos escritas nos cartazes, bem como mostrar para o restante da sociedade como as atividades das ocupações aconteciam6

No dia 6 de outubro de 2016, o Colégio Estadual do Paraná (CEP) foi ocupado. O CEP é o maior colégio público do estado. Assim, sua ocupação foi essencial no processo de ampliação das ocupações, uma vez que serviu como referencial organizativo, bem como ponto de encontro, onde as articulações entre as ocupações aconteceram.

Os processos de ocupação variaram em relação à preparação e ao número de pessoas envolvidas, bem como ao método da entrada dos estudantes e deflagração das ocupações. Além disso, variou no que diz respeito à dinâmica da ocupação em si, com a organização dos alojamentos, a divisão das tarefas e as atividades realizadas pelos ocupantes. No entanto, muitas das escolas basearam-se nos relatos das ocupações de São Paulo (CAMPOS; MEDEIROS; RIBEIRO, 2016), na cartilha que sistematizou a experiência chilena, chamada "Como ocupar um colégio" (O MAL EDUCADO, 2015), e na forma com que a ocupação do Colégio Estadual do Paraná se estruturou, uma vez que estudantes faziam visitas para ver o CEP para planejar a ação em seus respectivos colégios.

Em ato convocado no dia 6 de outubro, em apoio ao CEP, nós, do Levante, estávamos organizados com uma faixa, que havíamos produzido em atividade na ocupação do CEP, com a batucada e fazendo ação direta, com a colagem de lambes ao longo do trajeto. Ao final do ato, conversamos com os estudantes do C. E. Pedro Macedo, que nos contaram que estavam ainda mais animados para ocupar seu colégio e nos convidaram para contribuir no processo, pois identificaram no movimento uma referência de organização política que poderia ajudar na ocupação.

A mídia noticiou o processo de ocupações desde o início. O tom das notícias, no entanto, variou de acordo com o que podemos chamar de "mídia hegemônica" e de "mídia contra hegemônica", ou independente. A mídia contra hegemônica teve papel importante de difusão de informações sobre as ocupações, com dados em relação ao número de colégios ocupados no estado, bem como com debates acerca da MP 746 que foram utilizados como base formativa nas próprias ocupações. Os grandes veículos de comunicação, a princípio, noticiaram as ocupações como casos isolados e que não tendiam a crescer e se delongar. Com o passar dos dias e das semanas, começaram a veicular notícias sobre a falta de discernimento dos ocupantes, o prejuízo causado pelo remanejamento e sobre o adiamento de provas, como o vestibular da Universidade Federal do Paraná (UFPR) e do Exame Nacional do Ensino Médio (ENEM), bem como afirmaram que havia falta de organização do processo de ocupação. No dia 24 de outubro, um estudante

\footnotetext{
${ }^{5}$ As hashtags são como "etiquetas" virtuais que organizam os tópicos mais comentados, curtidos e compartilhados nas redes sociais. Os estudantes, ao ocuparem seus colégios, postavam fotos, depoimentos e informações que, com as hashtags, eram visualizados por milhares de pessoas de forma conjunta com as demais postagens sobre as ocupações.

${ }^{6}$ As ocupações de escolas no país, bem como outras recentes manifestações juvenis, têm como uma das características diferenciadoras das manifestações "tradicionais" a convocação e a mobilização por meio das Tecnologias de Informação e Comunicação (TICs) e de redes sociais como o Facebook (NOVAES, 2013). Esse processo aglutinador aconteceu nas manifestações citadas anteriormente, no México (VIDRIO, 2016), no Chile (AGUILERA RUIZ, 2014), em junho de 2013 (NOVAES, 2013, p. 22) e nas ocupações das escolas em São Paulo (CAMPOS; MEDEIROS; RIBEIRO, 2016).
}

Práxis Educativa, Ponta Grossa, v. 14, n. 3, p. 1121-1137, set./dez. 2019 Disponível em: <http://www.revistas2.uepg.br/index.php/praxiseducativa> 
morreu em uma escola ocupada e esse fato foi usado como exemplo, pela grande mídia, de como o movimento era perigoso e desorganizado.

A repercussão da morte do estudante na ocupação de um colégio, no bairro de Santa Felicidade, em Curitiba, demonstra como as notícias foram divulgadas ou omitidas, pois, antes desse fato, a imprensa quase não falava sobre as ocupações; e, se falava, era de forma negativa, como a matéria da gazeta do Povo, do dia 7 de outubro de 2016, que afirmava que os estudantes "não sabiam porque estavam ocupando"7.

O governador do estado do Paraná, Carlos Alberto Richa, lançou uma nota nas redes sociais, na qual reafirmava esse desconhecimento dos estudantes e "apelava" para os pais, para que proibissem seus filhos e suas filhas de ir para as ocupações, que eram "perigosas", como o assassinato evidenciara ${ }^{8}$.

\section{A ocupação do C. E. Pedro Macedo}

As militantes do Levante que estudavam no C. E. Pedro Macedo mantiveram-nos atualizadas do processo de mobilização da escola, onde houve algumas assembleias estudantis para tratar do assunto. A diretora, ao saber da articulação em curso, convocou o Grêmio Estudantil para uma conversa, na qual afirmou que havia comprado pães e salsichas para distribuir cachorro-quente no dia das crianças, e, por isso, pedia que o Grêmio freasse o processo de mobilização. Os estudantes sentiram-se coagidos e subestimados pelo pedido da diretora e seguiram organizando o processo de debates e na conformação de um grupo disposto a ocupar, sem informá-la do que estavam planejando.

No dia 11 de outubro, um grupo de cerca de 50 estudantes de todos os períodos letivos entrou no colégio, no final do turno noturno, e declarou que o colégio estava ocupado. Segundo as estudantes do Levante, o processo foi pacífico, a diretora estava presente na hora e os acusou de traição, mas concordou em se retirar, bem como os estudantes que se posicionaram de forma contrária, que reclamaram, mas saíram do colégio. Segundo os ocupantes, a reação da maioria dos estudantes do turno noturno foi de apoio à ocupação.

O Colégio Estadual Pedro Macedo é um dos maiores da regional Portãop , bairro em que

\footnotetext{
7 A reportagem "6 fatos que os estudantes das ocupações não sabem”, publicada pela Gazeta do Povo, foi bastante criticada pelos estudantes que ocuparam os colégios, pois afirmava que eles estavam sendo "utilizados" para projetos político-partidários, como se não tivessem discernimento para escolher ocupar e analisar o cenário político em que as ocupações aconteceram. A reportagem está integralmente disponibilizada no site do jornal. Disponível em: https://www.gazetadopovo.com.br/educacao/6-fatos-que-os-estudantes-das-ocupacoes-nao-sabemezs9mfd4wq6k5lmhxt5cq913k/. Acesso em: 21 mar. 2017.

8 “A morte do estudante Lucas Eduardo Araújo Mota, de 16 anos, é uma tragédia chocante, que merece uma profunda reflexão de toda a sociedade. É ainda mais gravíssimo e lamentável, porque aconteceu no interior de uma escola ocupada, que deveria estar cumprindo a sua missão de irradiar a luz do conhecimento e a formação da cidadania. Externo à família desse estudante a minha solidariedade neste momento tão doloroso. E renovo o meu apelo para que os pais redobrem o cuidado com seus filhos. Peço ainda, mais uma vez, que os estudantes encerrem esse movimento. A ocupação de escolas no Paraná ultrapassou os limites do bom senso e não encontra amparo na razão, pois o diálogo sobre a reforma do ensino médio está aberto, como bem sabem todos os envolvidos nessa questão. Que não se aleguem quaisquer justificativas para a continuidade desse movimento que vem causando prejuízos à educação do Paraná. É hora de responsabilidade e consciência sobre os direitos e deveres de estudantes, professores, famílias, autoridades e sociedade". Nota emitida por Beto Richa de São Paulo, em 24 out. 2016. Disponível em: https://www.facebook.com/BetoRichaOficial/posts/10154253163938800/. Acesso em 15 ago. 2017.

9 O C. E. Pedro Macedo está localizado em um bairro com características bastante específicas, que devem ser levadas em consideração nesta descrição. O Portão é um bairro limítrofe da área central de Curitiba, e está ao lado de bairros nobres, como o Água Verde e a Vila Izabel, e de bairros populares, como o Fazendinha, o Lindóia e o Novo Mundo.
}

Práxis Educativa, Ponta Grossa, v. 14, n. 3, p. 1121-1137, set./dez. 2019 Disponível em: <http://www.revistas2.uepg.br/index.php/praxiseducativa> 
E quando a experiência vira campo? Reflexões a partir da observação participante nas ocupações...

está localizado. O colégio oferta educação de nível fundamental e médio - regular, Educação de Jovens e Adultos (EJA) e profissionalizante. O colégio tem, ao todo, cerca de dois mil estudantes nos turnos matutino, vespertino e noturno. Os estudantes são oriundos de bairros bastante distintos do entorno do colégio, o que o caracteriza, nesse sentido, como um espaço de encontro entre estudantes que vivem na área central e na periferia de Curitiba.

No dia 12 de outubro, eu e outra companheira do Levante fomos ao colégio, para ver o que precisavam e como poderíamos nos inserir na ocupação. Na guarita de entrada, havia um grupo de estudantes, que nos disseram estar fazendo a segurança e ser necessária a apresentação de documento e assinatura em lista de registro, para entrarmos. Após assinarmos, uma estudante revistou-nos, reiterando a necessidade da averiguação para evitar a entrada de bebidas alcoólicas, substâncias ilícitas e armas.

Uma das secundaristas militantes do Levante recebeu-nos, apresentou o espaço da escola e falou-nos sobre como foi o processo da ocupação, que foi a base para este relato indireto do processo de ocupação. Ela falou ainda que a comissão de imprensa criou a página no Facebook, intitulada "Ocupa Pedro Macedo", que estava com uma boa repercussão, e que o apoio da comunidade estava ultrapassando as expectativas em relação à doação de alimentos e mensagens de solidariedade.

Segundo estudantes que se somaram ao longo dessa primeira conversa, era necessário realizar atividades durante o dia para que os estudantes fossem para o colégio. Oferecemo-nos para organizar uma grade com atividades e, nesse momento, acordamos nossa entrada na ocupação como apoiadoras ${ }^{10}$.

Havia cerca de 40 pessoas no primeiro dia em que fomos ao colégio, que era o segundo dia de ocupação. Os estudantes que participaram da assembleia pós ocupação já estavam com tarefas definidas. Assim, fomos apresentados aos responsáveis por cada uma das tarefas. Os demais estudantes, que chegaram depois da divisão inicial, somaram-se de acordo com a demanda e com a disponibilidade. Os estudantes que por motivos diversos - trabalho, proibição da família, cursinho pré-vestibular - não podiam dormir na ocupação, assumiram atividades conforme a demanda do dia.

Participamos da assembleia feita para organizar as atividades diárias. Um aspecto crucial observado em todos os momentos da ocupação, mas que, nesses espaços de encontro, se fez ainda mais marcante, foi o perfil dos ocupantes. A maioria era composta por mulheres estudantes. Um percentual grande era negro ou pardo, com características de valorização da negritude, como o cabelo black power e tranças raiz. Muitos deles, nas conversas mais iniciais, faziam questão de posicionar-se como LGBTTQIs. Destacamos que a ocupação, nesse sentido, para além de um espaço de reivindicação de uma demanda estrutural em relação ao Estado, que é a educação, era também, e tão importante quanto, um espaço de demandas interseccionais (DAVIS, 2016). Para além disso, muitos desses jovens tinham a estética punk dos cabelos coloridos e roupas pretas e customizadas, que pode ser entendida como forma de oposição à lógica do consumo e aos padrões normativos de beleza.

As pessoas que estavam no colégio, de maneira geral, participaram da assembleia. Uma das secundaristas do Levante, junto a outro estudante, coordenava o debate. Ainda que de forma pouco

\footnotetext{
10 Acredito que, pelo fato de duas estudantes do colégio serem do Levante, bem como por parte dos ocupantes ter conhecido outros militantes no ato dias antes, incluindo nós duas, a recepção em relação ao movimento foi bem diferente da que tivemos no CEP, quando nos pediram para tirarmos as camisetas e agir como indivíduos não organizados. Os estudantes do C. E. Pedro Macedo agradeceram a participação do movimento, convidaram-nos para dormir no colégio e pediram-nos para apresentar o Levante.
}

Práxis Educativa, Ponta Grossa, v. 14, n. 3, p. 1121-1137, set./dez. 2019 Disponível em: <http://www.revistas2.uepg.br/index.php/praxiseducativa> 
organizada, para os meus parâmetros de uma reunião do movimento estudantil ${ }^{11}$ - as pessoas falavam ao mesmo tempo; para chamar a atenção, era preciso gritar, os pontos não estavam bem divididos e os assuntos cruzavam-se e confundiam-se, não havia sistematização das decisões -, a assembleia deliberou quais seriam as atividades prioritárias do dia, alocou os participantes novos na tarefas existentes, retomou o debate sobre quem era a pessoa responsável por falar com a imprensa, para não haver discursos divergentes, e apresentou-nos "oficialmente" como apoiadoras da ocupação.

Os estudantes disseram-me que muitas pessoas da região passavam ao longo do dia perguntando o que eles precisavam e, naquela manhã, eles haviam feito uma lista e fixado no portão do colégio, para facilitar o processo de doações. Afirmaram que, apesar da aceitação parcial, uma parcela significativa dos moradores da região era contrária ao processo e se manifestou desde a ocupação, com gritos pelas janelas, intervenções de desacordo no portão e nas redes sociais. Os estudantes estavam desconfiando, nesse momento, que os vizinhos que moravam nos prédios ao lado da escola estavam observando a disposição espacial e as atividades da ocupação e delatando para a diretora.

Em conversas com diversos estudantes acerca de sua relação com a diretora do colégio, eles disseram que antes da ocupação ela era uma referência "confiável" e parceira do Grêmio Estudantil, com a qual estavam compartilhando informações e que se dizia favorável à ferramenta ocupação. Com o episódio da tentativa de atrasar a ocupação, ela foi desacreditada como parceira dos estudantes. Iniciou-se, assim, um atrito por parte de vários estudantes sobre a possibilidade da entrada dela no colégio e participação em atividades ${ }^{12}$.

$\mathrm{Na}$ hora do almoço, as pessoas que estavam nas outras atividades foram ao refeitório, onde a comida foi servida. Quando os estudantes entraram no colégio, a cozinha estava trancada, mas eles conseguiram abrir a porta. Contudo, estavam com receio de sofrer represálias por conta do uso do espaço. Eles separaram os alimentos que eram do colégio, destinados à merenda escolar, e utilizaram somente os equipamentos e os utensílios. Para além disso, restringiam o acesso à cozinha das pessoas que estavam na equipe; os demais se comunicavam por meio da janela que tinha no refeitório, onde ficava a bancada na qual as refeições foram servidas e os pratos e os talheres devolvidos, depois de limpos.

Como as doações foram variadas e numerosas, o almoço teve opção vegetariana, opção carnívora, suco e sobremesa. Duas coisas que me chamaram atenção em relação à tarefa da cozinha, desde o início, foram a escala das pessoas que trabalharam e a relação dos estudantes com os alimentos. A primeira surpreendeu-me porque, desde o princípio, o critério de paridade de gênero

\footnotetext{
11 A diferença em relação ao movimento estudantil, que podemos chamar de tradicional, foi, para mim, um estranhamento de saída - em que os formatos de condução dos debates e reuniões e as metodologias de sistematização já estão definidas e organizadas da seguinte forma: há uma pessoa que coordena a reunião, uma que relata o que é decidido e as demais participam, com inscrições, dos debates. É notório, também, que há uma forma estabelecida com que a oratória é desenvolvida, de forma pausada, acentuando os finais de frase. No entanto, acredito que há diversos elementos que podemos considerar comuns, como a própria organização em assembleia como espaço central para a organização da ocupação, por exemplo. Por hora, vale salientarmos que essa dicotomia se fez notória desde o princípio de minha participação na ocupação, mas que os aspectos comuns também estavam presentes.

$12 \mathrm{O}$ fato de ela poder ou não participar foi colocado em pauta porque outras professoras e professores que se declararam favoráveis à ocupação estavam frequentando o colégio ocupado, doando alimentos e auxiliando os ocupantes no diálogo com a comunidade escolar - um deles inclusive emprestou uma televisão para os ocupantes. Eles afirmaram que a diretora estava se posicionando de maneira contrária a eles no grupo de Whats $A p p$ de funcionários do colégio. Alguns dos estudantes que estavam na conversa afirmavam que ela não devia estar se opondo, que devia ser uma leitura apressada dos professores e que uma mediação era necessária para garantir a estabilidade e a não repressão em relação à ocupação. O debate na cozinha terminou com a necessidade de levar esse ponto para ser apreciado em assembleia, a fim de definir uma postura da ocupação em relação à diretora do colégio.
}

Práxis Educativa, Ponta Grossa, v. 14, n. 3, p. 1121-1137, set./dez. 2019 Disponível em: <http://www.revistas2.uepg.br/index.php/praxiseducativa> 
E quando a experiência vira campo? Reflexões a partir da observação participante nas ocupações...

foi colocado como um fator para escolher as pessoas que iriam cozinhar. As mulheres, ainda que "soubessem cozinhar melhor e fizessem mais rápido", não ficaram com a exclusividade da tarefa. A segunda foi a relação dos estudantes com os alimentos que eram da merenda do colégio e com as doações de alimentos que receberam para a ocupação. Eles decidiram, no começo da ocupação, que tudo que era doado era para ser consumido livremente, "com bom senso", segundo eles. Assim sendo, eles colocaram todos os alimentos em um canto do refeitório onde o acesso era irrestrito, diferente do espaço da cozinha que estava limitado às pessoas que estavam com a tarefa. Essa decisão foi rapidamente reavaliada, pois os grupos que ficavam acordados durante a madrugada para a tarefa da segurança e os que ficavam conversando - estavam comendo todas "as coisas boas", como os doces, chocolates e biscoitos.

O período da tarde teve maior adesão estudantil, ultrapassando o número de 80 ocupantes. Parte deles ficou na entrada do colégio, conversando com o grupo que fazia a segurança. Outra parte estava dentro do colégio, limpando os banheiros e espaços comuns, jogando bola, andando de skate no pátio e em rodas de conversa. Muitos dos estudantes me relataram, nesses primeiros dias, como a noção do próprio espaço escolar estava se transformando com a ocupação, pois a realização das tarefas os fazia olhar para o colégio de forma mais envolvida e comprometida. É importante salientar que esses jovens, com média de idade entre 14 e 17 anos, ainda moravam com pais ou responsáveis, e muitos não tinham a necessidade de realizar atividades domésticas. Para muitos, portanto, a ocupação foi o primeiro espaço de contato com as tarefas “adultas". É notório, ainda, que a maioria destes que nunca tinham limpado um banheiro, ariado panelas e varrido um pátio eram homens, que foram inseridos nas tarefas de limpeza por demanda das mulheres, que afirmavam, desde o início, que estavam tentando construir um processo paritário. Elas, por sua vez, assumiram tarefas como a segurança - diurna e noturna -, coordenação das atividades de maneira geral e diálogo com a imprensa e com a direção, em um esforço de construção igualitária.

As mulheres estudantes colaram cartazes com frases feministas no colégio, bem como os LGBTTQIs e negras/os. As conversas muitas vezes giravam em torno da temática interseccional (DAVIS, 2016), tanto entre iguais quanto no diálogo com os demais. Ocupantes que "não ouviam" eram repreendidos e chegou a formar-se uma comissão para avaliar situações de opressão, encaminhando uma conversa mais direta e enfática com um rapaz que estava fazendo comentários que avaliaram como machistas. A questão de gênero, raça e orientação e identidade sexual eram, portanto, paralelas a todas as atividades da ocupação. Na hora da divisão de tarefas, falava-se do trabalho doméstico como incumbência feminina. No entanto, necessidade da paridade nas tarefas que poderiam ser consideradas domésticas, como a alimentação, bem como nas tarefas como a segurança, que podiam ser consideradas masculinas, as mulheres exigiam participar.

Na primeira noite em que dormi na ocupação, levaram-me ao dormitório, que tinha acesso restrito por questões de segurança, segundo os ocupantes. Os colchões infláveis trazidos de casa e os tapumes de ginástica que também serviam de colchões foram posicionados em um único quarto, que estava sendo compartilhado por todas as pessoas que ocupavam. A justificativa para a indiferenciação de gênero era da segurança, uma vez que cerca de 20 pessoas estavam dormindo no colégio. Desse modo, se houvesse algum problema à noite, seria mais fácil dar um direcionamento se estivessem todos em um mesmo local. No entanto, disseram-me que, quando questionados sobre o alojamento por pessoas de fora da ocupação, respondiam que era dividido entre masculino e feminino, pois eram menores de idade, e os pais não consentiriam se soubessem a dinâmica de organização, ainda que com a justificativa de garantir a segurança.

$\mathrm{Na}$ manhã seguinte, acordamos e fomos preparar o café. Aos poucos, os demais foram acordando e descendo para o refeitório. Não havia um horário único para acordar e comer, e os ocupantes que dormiram no colégio e os que chegaram de manhã para as atividades do dia foram

Práxis Educativa, Ponta Grossa, v. 14, n. 3, p. 1121-1137, set./dez. 2019 Disponível em: <http://www.revistas2.uepg.br/index.php/praxiseducativa > 
se aglomerando em torno da sala de reuniões para a assembleia.

A assembleia aconteceu no meio da manhã, em uma dinâmica similar à do dia anterior, com duas pessoas coordenando o espaço. Nesse segundo dia, até mesmo eles me disseram que acharam mais difícil realizar o espaço sem uma proposta metodológica e nos pediram ajuda para organizar a próxima. Explicamos, com base no que era a metodologia comum no movimento estudantil tradicional, o que era a pauta (predefinição de pontos a serem debatidos), a inscrição para estabelecer uma ordem para as falas e a relatoria, que poderia conter dados como quantidade de participantes, descrição dos debates ou somente os encaminhamentos destes. A ocupação pode ser pensada, com base nesse exemplo, como um espaço formativo acerca do fazer a política, em que experiências são articuladas e transmitidas, como performances que adensam os repertórios políticos (TAYLOR, 2014).

Organizamos um quadro inicial com as atividades que havíamos articulado no dia anterior com militantes do Levante e com parceiros, educadores e artistas. Havia uma equipe na ocupação responsável pela agenda, com a qual conversamos para mostrar a proposta das atividades.

Um ponto a ser ressaltado é sobre as tentativas de articulação entre as ocupações. Essas tentativas de organização de unidade entre as ocupações aconteceram em dois âmbitos distintos, que, por ora, se interpuseram, mas que, durante o processo, se distanciaram. O primeiro foi a tentativa de organização de assembleias com representantes das ocupações de um mesmo bairro e região de uma cidade, e assembleias no âmbito municipal. Essa tentativa, de caráter autonomista, teve como base a autogestão e a participação ampla. As assembleias aconteceram principalmente municipalmente, organizadas de forma hegemônica pelo Colégio Estadual do Paraná, que serviu como espaço de encontro para esses momentos de articulação política das ocupações. Os estudantes do C. E. Pedro Macedo estavam se revezando para participar dessas reuniões e, quando questionei se estavam sendo positivas, me responderam que sim, mas que havia muitas disputas políticas e poucas propostas de construção unitária de fato.

A segunda tentativa de organização unitária aconteceu com o protagonismo da União Paranaense de Estudantes Secundaristas (UPES), que é a entidade que tem o objetivo de organizar e representar os secundaristas do Paraná. A direção da entidade deu entrevistas para a grande mídia sobre os processos de ocupação, bem como tentou participar das assembleias e dos espaços de organização e de deliberação dos estudantes. Em um primeiro momento, essa integração entre as tentativas de organização autonomista, ou direta, e de organização centralizada na UPES coexistiu e, ainda que com críticas e apontamentos das duas partes, as resoluções tomadas contemplaram ambas.

No entanto, uma primeira cisão aconteceu em relação ao diálogo com o Governo Estadual. A gestão do Beto Richa convocou os estudantes ocupados para reuniões de negociação em relação à pauta, uma vez que a MP 746, apesar de âmbito Federal, garante ao estado certa liberdade em relação a sua aplicação. O segmento auto-organizado opôs-se ao processo de negociação com o Governo e convocou as escolas ocupadas a boicotarem as reuniões, enquanto a UPES se colocou como representante e buscou articular estudantes para participarem das reuniões. Os estudantes do C. E. Pedro Macedo entraram em contato com representantes da UPES e foram a uma primeira reunião convocada pela entidade, sem saber ao certo qual a metodologia estava sendo proposta. Quando chegaram e se depararam com representantes do estado, ficaram bravos e voltaram ao colégio afirmando que se sentiram enganados pela convocatória da reunião.

Os estudantes do C. E. Pedro Macedo estavam se revezando para participar, portanto, desses dois espaços de articulação das ocupações, que aconteciam em paralelo e com metodologias e táticas distintas, de auto-organização e de mediação com o Governo Estadual. Acredito ser

Práxis Educativa, Ponta Grossa, v. 14, n. 3, p. 1121-1137, set./dez. 2019 Disponível em: <http://www.revistas2.uepg.br/index.php/praxiseducativa > 
E quando a experiência vira campo? Reflexões a partir da observação participante nas ocupações...

relevante ressaltar que, nas assembleias que organizavam no colégio, a participação era pautada como importante, ainda que fosse crítica aos dois espaços.

Ruiz (2014) afirma que uma das leituras possíveis sobre os movimentos juvenis de estudantes é a "desconfiança com as entidades representativas". Essa desconfiança, ainda que notória, como explicitado anteriormente, não anula a importância das entidades, uma vez que elas seguem sendo uma via de organização e de diálogo entre os estudantes e/ou esferas estatais. Para além da efetividade das entidades, a horizontalidade, colocada como oposta à representatividade, na prática, também funciona com a participação seletiva e com afinidades político-ideológicas, majoritariamente de caráter anarquista e autonomista. Podemos afirmar, nesse sentido, que as manifestações se organizam de forma a mesclar a representatividade e a horizontalidade, sem assumir uma única orientação metodológica e política. No entanto, na ordem do discurso, a negação das entidades e a afirmação da horizontalidade das instâncias aparece como a forma organizativa do movimento como um todo.

Durante a ocupação foram realizadas diversas oficinas - de break, estêncil, dança, de bolha de sabão gigante, de birutas - rodas de conversa - sobre a democratização dos meios de comunicação, sobre o Movimento dos Trabalhadores Rurais Sem Terra (MST) e agroecologia, sobre o feminismo - e aulas preparatórias para o vestibular e o ENEM - de matemática, produção de texto, história. As/os estudantes estavam participando das atividades e todos diziam ser uma experiência positiva estar em espaços formativos em formatos distintos das aulas convencionais. A relação com a escola, nesse sentido, fora atualizada pelos ocupantes, pois se identificavam como mantenedores do espaço, proponentes das atividades e participantes de forma voluntária.

Outro ponto levantado por diversos ocupantes foi a integração que a ocupação proporcionou. Segundo eles, as "panelinhas" do cotidiano deram espaço a uma maior interação, em que os parâmetros não eram o ano escolar ou a turma, o que fez com que as pessoas interagissem para além das relações preestabelecidas pelo ambiente escolar. Escutei ainda diversos relatos, ao longo da ocupação, de como esse contato com pessoas novas ampliou a visão dos estudantes sobre a própria condição juvenil e propiciou o estreitamento de vínculos afetivos.

Um relato em específico me marcou bastante, pois havia na ocupação um estudante de dezesseis anos que estava passando pela transição de gênero. Ele entrou no colégio C. E. Pedro Macedo no início de 2016 e, ao longo do ano, passou a se identificar no gênero masculino, ou seja, como um adolescente transgênero. Um colega, que estudava com ele na escola anterior, relatoume que nunca havia tentado conversar sobre a identidade de gênero e como era preconceituoso quando se dirigia a ele. Na ocupação, em conversas diretas e com outras pessoas, que acompanhavam o processo de transição mais de perto, ele pôde compreender o que era identidade de gênero, como se dirigir a ele, quais os pronomes adequados e me dizia orgulhoso que estava disposto a acompanhá-lo mais de perto. Concluiu essa conversa afirmando que ele "aprendeu a respeitá-lo e iria defendê-lo", caso algum outro colega o ofendesse, e se orgulhou de ser capaz de explicar o que era a transição e como deveria proceder para não gerar desconforto.

Houve, nesse sentido, uma ampliação das redes de amizade e de solidariedade que já existiam no colégio, mas que se mesclaram, formando o que eles chamaram de família. Eles brincavam com isso, que, quando acabasse a ocupação e a escola voltasse à dinâmica convencional, eles iriam trocar de turmas para poderem seguir juntos.

Não estou afirmando, no entanto, que a ocupação foi um espaço sem atritos e disputas internas entre os estudantes. Ao contrário, a metodologia adotada por eles de decidir as coisas em assembleia, que deveriam ser seguidas pelas equipes e pelos ocupantes, na prática, gerou vários processos de contradição entre propostas e encaminhamentos que desencadearam atritos entre as

Práxis Educativa, Ponta Grossa, v. 14, n. 3, p. 1121-1137, set./dez. 2019 Disponível em: <http://www.revistas2.uepg.br/index.php/praxiseducativa > 
pessoas envolvidas.

Uma situação em que observei essa disparidade entre o discurso em torno da ocupação e a prática foi entorno da aproximação de estudantes para se somarem nas atividades e na dinâmica da ocupação. Os ocupantes afirmavam com frequência que a ocupação era feita por autogestão e que todas as pessoas envolvidas tinham capacidade semelhante de se envolver e decidir. No entanto, após a segunda semana, as pessoas que estavam nas equipes e haviam assumido protagonismo nas tarefas estavam sendo vistas como referências, no que tangia à coordenação das atividades específicas referentes àquela tarefa, mas não eram legitimadas para falarem como tal, nos espaços de assembleia e no próprio cotidiano da ocupação. $\mathrm{O}$ exemplo mais explícito em que isso aconteceu foi em relação à tarefa da limpeza, que, no começo, era incumbência de uma equipe. Uma das participantes da equipe destacou-se nesse processo, pois organizava os grupos de limpeza com facilidade e sabia onde estavam os materiais de limpeza, quais as demandas de doação e quantas pessoas era necessário acrescentar na tarefa, com base na participação flutuante diária. Os demais participantes da equipe começaram, com o passar dos dias, a "esperar" que ela "mandasse" para começarem a fazer a limpeza e, ao mesmo tempo, reclamavam que ela estava "se achando" a chefe, e, por isso, não faziam o que ela dizia ser necessário, mas, na prática, tampouco faziam o que eles mesmos achavam ser preciso de forma auto-organizada. Na segunda semana de ocupação, ela já estava afirmando estar brava com todos os companheiros de equipe e não propunha mais a arrumação, que passou a ser feita por meio de mutirões porque a equipe se desfez.

Durante a noite, as pessoas ficavam acordadas em um grupo cada vez maior, e até mais tarde, com o pretexto de fazer companhia à equipe de segurança e garantir seu reforço, jogando baralho, comendo e conversando. Na primeira semana, a dinâmica de organização da ocupação começou a mudar, pois as noites estendidas geraram um processo de desmobilização da manhã as assembleias estavam começando quase na hora do almoço, de forma desorganizada e com pauta quase sempre relativa à noite anterior e aos problemas em decorrência dessa dinâmica. Uma das questões identificadas pelos estudantes foi que, à noite, o grupo que ficava acordado comia tudo o que queria - não se importando com o restante dos ocupantes - e fazia bagunça na cozinha e nos banheiros.

As equipes estavam se enfraquecendo e deixando de ter uma organicidade. As tarefas como alimentação e segurança foram se tornando rotativas. A cozinha estava cada vez mais suja e bagunçada porque, à noite, cada estudante ia e comia o que queria, na hora em que sentia vontade e, de forma geral, não arrumava o que havia utilizado.

Um estudante informou aos ocupantes que a diretora estava organizando uma reunião para definir o que fazer em relação à ocupação, com a justificativa de que os estudantes estavam, na verdade, "vandalizando o colégio e fazendo coisas ilícitas". Nessa reunião, eles encaminharam a criação de uma página no Facebook, intitulada "Desocupa Pedro Macedo", e marcaram um ato de desocupação para o dia 24 de outubro, em frente ao colégio. A página "Desocupa Pedro Macedo" fez a convocatória para o ato em frente ao colégio e começou a se vincular com as demais páginas de desocupações de outros colégios, bem como a vincular notícias do Movimento Brasil Livre (MBL).

Os ocupantes, após a reunião de organização desse ato pró-desocupação, buscaram contatos de estudantes que participaram, para tentar antever o que estavam planejando. Sem sucesso, souberam do ato somente quando a página contrária à ocupação divulgou. Temerosos em relação ao número de adeptos, começaram a convocar apoiadores da ocupação para comparecer à frente do colégio, no horário marcado pelos que estavam contrários à ocupação. Os atos não tiveram assiduidade e rapidamente se dispersaram.

Práxis Educativa, Ponta Grossa, v. 14, n. 3, p. 1121-1137, set./dez. 2019 Disponível em: <http://www.revistas2.uepg.br/index.php/praxiseducativa > 
E quando a experiência vira campo? Reflexões a partir da observação participante nas ocupações...

Nos dias em que a tensão estava aumentando, entre os ocupantes e os estudantes contrários, percebi que a dinâmica da ocupação estava diferente. Os ocupantes estavam preocupados e irritados e os conflitos que, no começo eram resolvidos em conversas, estavam gerando brigas e desacordos. Um grupo pequeno assumira o papel de mediação dessas situações e estava sendo considerado o grupo dirigente da ocupação, o que gerava outros atritos e reclamações, pois eles se declaravam auto-organizados. O que estava em questão era, principalmente, se todas as decisões deveriam ser tomadas nas assembleias, ou se um grupo reduzido podia planejar e apenas apresentar a proposta no espaço mais geral. Essa segunda opção foi adotada na maior parte das vezes na organização da ocupação; dessa forma, cada grupo levantava as demandas de sua tarefa e repassava em assembleia o que havia sido encaminhado.

Em uma tarde em que chegamos na ocupação, eles estavam falando que estavam cansados. Nós havíamos levado a caixa de som do Levante para a ocupação e decidimos usá-la para fazer uma mística com os ocupantes, para tentar animar o grupo. A mística é uma ferramenta utilizada pelos movimentos sociais que tem como objetivo tratar das questões políticas de forma sensível, que não pelo debate convencional, por meio de músicas e poesias e de exercícios de afeto e cuidado (BOGO, 2002).

O acirramento em torno das ocupações aumentava. Com a morte de um estudante no dia 24 de outubro, a mídia hegemônica e o governo do Estado reiteravam os pedidos de desocupação. No dia 26 de outubro, uma estudante secundarista, chamada Ana Júlia Pires Ribeiro, fez um pronunciamento na Assembleia Legislativa do Paraná e teve grande repercussão nas redes sociais (SCHMIDT; DIVARGIM; SOBANSKI, 2016, p. 76-80).

Podemos afirmar, nesse ponto, que o processo das ocupações estava sendo disputado, como fato público, pelos ocupantes e pela grande mídia. A narrativa de que o processo de ocupações estava se esgotando e ficando cada vez mais desorganizado e perigoso, veiculado pela mídia hegemônica, cada vez mais se sobrepôs. Um exemplo de como essa disputa foi aos poucos se delineando foi a quantidade de pais e de mães de estudantes que ocuparam, que, ainda que favoráveis à ocupação, depois da morte do estudante, proibiram seus filhos e suas filhas de seguir ocupando seu colégio, por insegurança.

As ocupações começaram a ampliar-se para além dos colégios estaduais e Institutos Federais (IFs), chegando também às Universidades (Estaduais e Federais) e Núcleos de Educação. No dia 25 de outubro, o número de instituições ocupadas era de 995 escolas e Institutos Federais, 73 campi universitários, 3 Núcleos Regionais de Educação, além da Câmara Municipal de Guarulhos, o que totaliza 1.072 locais ocupados. Destas, 880 instituições de ensino ocupadas estavam no Paraná ${ }^{13}$.

Fazia décadas que esse processo de articulação entre secundaristas e universitários não acontecia no movimento estudantil brasileiro; desse modo, podemos considerá-lo como uma das "conquistas" das ocupações de 2016. Além disso, essa quantidade de instituições de ensino ocupadas configura, podemos afirmar, o maior processo de mobilização estudantil do mundo. Os pingüinos, secundaristas chilenos, ficaram conhecidos por fazer marchas massivas, em 2011, com a ocupação de cerca de 700 escolas e milhares de estudantes nas ruas, semanalmente, em luta pela educação pública e gratuita. A quantidade de pessoas mobilizadas no Chile foi a maior até então e

\footnotetext{
${ }^{13}$ Os universitários ocuparam a Universidade Federal do Paraná no dia 26 de outubro. A ocupação da UFPR teve repercussão positiva entre os secundaristas, que já se diziam cansados e em uma dinâmica de enfraquecimento das ocupações nos colégios, no que tange à participação de estudantes para além dos grupos mais restritos que, na prática, sustentaram as ocupações até o final. Outras universidades estavam ocupadas em outros estados brasileiros e começava-se a falar, nas ocupações dos colégios, que, conforme as reintegrações de posse começassem a ser expedidas, os universitários poderiam assumir o protagonismo, dando continuidade às ocupações.
}

Práxis Educativa, Ponta Grossa, v. 14, n. 3, p. 1121-1137, set./dez. 2019 Disponível em: <http://www.revistas2.uepg.br/index.php/praxiseducativa> 
o movimento se tornou referência pela irreverência e pelas novas táticas utilizadas pelos estudantes, como o malabarismo, as fantasias e a marcha dos guarda-chuvas (AGUILERA RUIZ, 2014; O MAL EDUCADO, 2015).

No dia 27 de outubro, a Justiça Estadual acatou um segundo pedido de reintegração de posse feito pelo governo do estado e determinou a reintegração de 25 escolas ocupadas no Paraná. Houve uma tentativa de negociação com os estudantes ocupados, que se comprometeram a desocupar os colégios nos bairros e nas cidades do interior para a manutenção da ocupação do Colégio Estadual por mais dez dias. No entanto, essa negociação não foi legitimada por uma expressiva parcela dos estudantes ocupados, que se recusaram a sair de seus colégios, como havia sido acordado com a representante do estado. O Governo começou, então, a cumprir os pedidos de reintegração de posse, sem realizar novo acordo com os estudantes, estabelecendo uma multa diária de dez mil reais para os estudantes que descumprissem a medida de desocupação dos colégios. Os estudantes não resistiram à saída dos colégios listados e o Governo deixou o CEP por último, ao que tudo indica, para evitar confrontos.

$\mathrm{Na}$ noite do dia 27 de outubro, integrantes do MBL tentaram desocupar, ainda que sem ordem judicial, o Colégio Lysimaco Ferreira da Costa, no bairro Água Verde. Os manifestantes entraram no colégio com o diretor e começaram um conflito com os estudantes ocupados.

As ocupações dos colégios passaram, depois da última semana de outubro, a cair em quantidade, enquanto as ocupações de universidades passaram a aumentar. Isso aconteceu porque muitas já caminhavam para a terceira semana de ocupação; assim, os ocupantes estavam sendo tensionados pela comunidade e pela direção (impulsionados pelo MBL) e pelas famílias (impulsionadas pela mídia).

$\mathrm{Na}$ ocupação do C. E. Pedro Macedo, os sinais de desgaste estavam aumentando. $\mathrm{Na}$ manhã do dia 28 de outubro, acordei com o despertador do celular e os estudantes ainda dormiam. Fui fazer o café e eles começaram a levantar e ir para a cozinha. Já passava do meio da manhã quando todos estavam de pé. Perguntei se haveria assembleia e me disseram que não estava acontecendo regularmente, mas conforme a demanda. Não havia, portanto, organização das atividades do dia.

Alguém disse que viu um evento no Facebook, organizado pelos estudantes contrários à ocupação, convocando um ato de desocupação para o início da noite. Passamos a tarde mobilizando a rede de apoiadores, entre eles estudantes do próprio colégio, das universidades, militantes de movimentos sociais e coletivos do movimento estudantil, artistas, sindicalistas, advogados. Fomos avisados que o MBL estava com um caminhão de som em uma esquina próxima ao colégio, reunindo um grupo de pessoas para se posicionar em frente à escola. Alguns estudantes foram ver e disseram que havia cerca de 50 pessoas. Nós reunimos os apoiadores que já estavam em frente ao colégio e pedimos para que mandassem mais mensagens de convocação para uma ação de defesa da ocupação.

Os manifestantes contrários caminharam até a entrada do colégio, sem o caminhão de som, e se posicionaram na calçada em frente, ao lado do tubo de ônibus. Um deles, conhecido por sua atuação no MBL, estava com um megafone, camiseta do movimento e puxava gritos de ordem contrários à ocupação, que era cantado por todos que estavam com ele. Os gritos não se restringiam à temática da ocupação, acusando os ocupantes de serem comunistas, petistas, conclamando uma ação truculenta da polícia. A diretora do colégio estava junto aos manifestantes contrários, gritando. Outros professores também cantavam e gritavam "vai pra Cuba", "fora petralhas".

A mobilização a favor da ocupação reuniu centenas de pessoas e tomou toda a frente do

Práxis Educativa, Ponta Grossa, v. 14, n. 3, p. 1121-1137, set./dez. 2019 Disponível em: <http://www.revistas2.uepg.br/index.php/praxiseducativa > 
E quando a experiência vira campo? Reflexões a partir da observação participante nas ocupações...

colégio, formando uma corrente de isolamento do colégio. Esse conflito durou cerca de quatro horas e não houve nenhuma situação de violência física, se configurando, portanto, como ideológico, cujos posicionamentos estavam territorialmente demarcados em lados da rua e nos gritos de ordem e música entoados pelos diferentes grupos. Já era noite quando as manifestações começaram a se dispersar. A manifestação teve repercussão nacional, tanto nas redes favoráveis à ocupação quanto nas contrárias.

No início de novembro, a ocupação do C. E. Pedro Macedo já estava bastante desgastada. Os estudantes que participavam assiduamente do processo estavam se revezando para acompanhar outros espaços de mobilização, como as ocupações das universidades, dos núcleos de ocupação e dos espaços de articulação entre os colégios que seguiam ocupados. A tônica do discurso sobre a ocupação estava mudando, já não era mais de "vamos ocupar até o Temer retirar", tratando da MP 746, como afirmavam no começo, mas, sim, de que o movimento já havia sido vitorioso e que desocupar não era "abandonar a causa" ou desistir. Alguns colégios já haviam desocupado espontaneamente e eram usados como exemplo. Em conversas informais e em assembleia, decidiram, no entanto, aguardar a reintegração de posse para desocuparem o colégio.

No dia 3 de novembro, a reintegração foi expedida, junto a outros 40 colégios que seguiam ocupados. Os estudantes do C. E. Pedro Macedo foram informados da decisão judicial por meio do documento que circulou nos grupos de Whats App e no Facebook. A notícia foi rapidamente difundida entre eles e houve uma reunião para conversar sobre o que fariam quando o oficial de justiça chegasse. Eles consultaram advogados, foram avisados que o processo estava acontecendo de forma pacífica nos demais colégios e decidiram não resistir.

A oficial de justiça chegou acompanhada de uma assistente social, de representante do Ministério Público Estadual e de policiais militares. Ela chamou os estudantes no portão do colégio, entregou o Mandato de Reintegração de Posse e disse que, por parte deles, o processo de retirada seria pacífico. Quando terminaram de retirar os materiais do colégio, os estudantes saíram e formaram um cordão em frente ao colégio. Puxaram gritos de ordem e, com um megafone, leram o manifesto de desocupação que haviam feito naquela manhã:

\section{NOTA OFICIAL | MANIFESTO DE DESOCUPAC̄̃O |}

Nós acusamos, O GOVERNO FEDERAL na figura de Michel Temer e seu ministro da educação, por buscarem alterar o ensino médio desqualificando a formação humana e reforçando o dualismo no ensino médio brasileiro. Fazem isso com um discurso que se traveste de inovador, mas aprofundará desigualdades históricas da educação brasileira. Nós acusamos, O PODER JUDICIÁRIO, que desrespeita princípios básicos do Estado Democrático de Direito e fornece ao executivo e seus braços armados documentos para colocar medo e tentar diminuir a resistência dos estudantes. Nós acusamos, A MíDIA HEGEMÔNICA, que ignora o maior movimento secundarista da história. Não obstante, trabalha sistematicamente apoiando o faminto neoliberalismo que se alimenta do desmonte dos serviços públicos. Nós acusamos, OS PROFESSORES QUE TEMEM A GREVE E A DESOBEDIÊNCIA CIVIL. Saibam que estão encurralados, de um lado a PEC 241 (agora PEC 55) e de outro, estudantes endurecidos e amadurecidos nas ocupações. Sairemos das escolas muito mais conscientes do que quando entramos. Durante as ocupações aprendemos e ensinamos. Aos pequenos grupos fascistas que tentam nos afrontar damos um aviso: vocês são poucos e pequenos e por isso venceremos vocês nas ruas. Nós, estudantes secundaristas, saímos hoje, sexta-feira (04), da nossa escola muito conscientes de nossas ações. Não saímos apenas com a crença no futuro. Saímos para tomar a cidade e continuar construindo, nós, por nossas mãos, o futuro que desejamos.

\#OCUPATUDO\#NãoPec\#ForaTemer\#SecundaristasResistem \#AlutaContinua\#JUVENTUDERESISTE\#OCUPAPEDRÃO \#PrimaveraSecundarista \#OcuparEResistir. (OCUPA PEDRO MACEDO, 2016).

Práxis Educativa, Ponta Grossa, v. 14, n. 3, p. 1121-1137, set./dez. 2019 Disponível em: <http://www.revistas2.uepg.br/index.php/praxiseducativa $>$ 
Eles seguiram puxando gritos de ordem por mais um tempo, enquanto esperavam a oficial de justiça e os policiais irem embora. Logo que saíram do portão, a diretora pegou um alicate e cortou os cadeados que trancavam o portão do estacionamento do colégio. Os estudantes informaram, nos grupos de Whats $A p p$, que a reintegração do C. E. Pedro Macedo terminara e que a oficial de justiça estava se deslocando para o próximo colégio, para que os demais estudantes se preparassem. Eles lançaram o manifesto de desocupação nas redes sociais e ficaram mais um tempo em frente ao colégio, cantando e dançando.

\section{Esboçando uma conclusão}

O objetivo de trazermos partes do trabalho de campo da dissertação de Mestrado Ocupar e resistir: as ocupações das escolas públicas como parte do ciclo atual de mobiliz̧ação juvenil no Brasil, de Carolina Simões Pacheco, no presente texto, foi o de evidenciar questões que emergiram durante a experiência como apoiadora das ocupações, a partir de uma reflexão sistematizada. Cabe ressaltarmos, assim, a própria condição de engajamento como o ponto de partida da pesquisa, em que a prática militante se coloca como condição para o estabelecimento do vínculo de apoiadora. Não que sem ser militante o campo não pudesse ser feito; acreditamos, no entanto, que o nível de entrega de ambas as partes na situação vivenciada pode ser entendido como intenso, na medida em que a relação que posteriormente iria se configurar como "pesquisadora/interlocutor/a", nesse momento, estava pautada em outra base, em que ambos estavam na posição de engajamento, trocando e compartilhando experiências no "fazer política". Destacamos, nesse sentido, as reflexões de Diana Taylor (2014) sobre as práticas políticas como performances que conformam repertórios, que podem ser aprendidos, transmitidos e ensinados como experiências políticas. $\mathrm{O}$ campo começou, assim, como um momento de troca, que, posteriormente se configurou em algo que se aproxima do que Wacquant (2002) destacava como a sistematização reflexiva da própria experiência a partir do olhar sociológico. O campo de pesquisa, nesse sentido, é resultado de uma interação primeira que foi vivida e percebida por mim e pelos ocupantes como uma relação militante e, posteriormente, ressignificada como uma relação de pesquisa.

Essa mudança de posição gerou medo e angústia em mim, em relação a como aqueles que se tornariam "meus interlocutores" iriam reagir à essa mudança. Durante a pesquisa, eu tive dificuldade em assumir essa nova postura e convidar as pessoas que ocuparam para participar de entrevistas. No entanto, à medida que me senti mais confortável para explicar a proposta de pesquisa, percebi que a recepção deles era positiva e ultrapassava minhas expectativas.

Acredito que isso se deve ao fato de que nossa relação primeira era pautada na confiança que, ainda que em outros termos, podia ser realocada para essa nova condição. Outro ponto que me chamou a atenção nesse novo contato foi o silêncio no espaço escolar após as ocupações. Não somente as pessoas que ocuparam o C. E. Pedro Macedo, mas diversos estudantes com os quais tivemos contatos a partir do grupo de pesquisa falam sobre o retorno ao cotidiano escolar marcado pelo silêncio das direções em torno das ocupações. As/os professoras/es que apoiaram as ocupações foram alvo de denúncias e vários deles respondem a processos administrativos, reforçando esse silenciamento no ambiente escolar em torno dessa experiência política. Ressaltamos, portanto, a necessidade de ocuparmos também os espaços acadêmicos para tratarmos das temáticas juvenis, educacionais e políticas que são reiteradamente silenciadas e invisibilizadas no cotidiano escolar.

Concluímos este artigo esboçando um ponto já desenvolvido por Tarrow (2002) em sua formulação sobre os ciclos de mobilização. Entre um ciclo e outro existe o momento de latência, em que os acúmulos do ciclo passado organizam redes quase imperceptíveis e submersas que gestam o novo. Apesar de aparentemente espontâneo e intermitente, esse processo de mobilização

Práxis Educativa, Ponta Grossa, v. 14, n. 3, p. 1121-1137, set./dez. 2019 Disponível em: <http://www.revistas2.uepg.br/index.php/praxiseducativa> 
E quando a experiência vira campo? Reflexões a partir da observação participante nas ocupações...

pode ser compreendido como parte de uma tessitura de mobilizações políticas que questionam assimetrias e desigualdades enraizadas e fazem parte deste gérmen do novo.

\section{Referências}

BOGO, A. O vigor da mística. São Paulo: MST, 2002. (Caderno de Cultura No 2).

BRASIL. Medida Provisória No - 746, de 22 de setembro de 2016. Institui a Política de Fomento à Implementação de Escolas de Ensino Médio em Tempo Integral, altera a Lei no 9.394, de 20 de dezembro de 1996, que estabelece as diretrizes e bases da educação nacional, e a Lei no 11.494 de 20 de junho 2007, que regulamenta o Fundo de Manutenção e Desenvolvimento da Educação Básica e de Valorização dos Profissionais da Educação, e dá outras providências. Diário Oficial da União, Brasília, DF, 23 set. 2016.

CAMPOS, A. M.; MEDEIROS, J.; RIBEIRO, M. M. Escolas de luta. São Paulo: Veneta, 2016. (Coleção Baderna).

DAVIS, A. Mulheres, raça e classe. São Paulo: Editora Boitempo, 2016.

HONNETH, A. Luta por reconhecimento: a gramática moral dos conflitos sociais. São Paulo: Editora 34, 2003.

NOVAES, R. C. Juventude: políticas públicas, conquistas e controversias. In: BEOZZO, J. O.; FRANCO, C. B. (Orgs.). Juventudes em Foco. São Paulo: Paulus, 2013. p. 39-74.

O MAL-EDUCADO. Como ocupar um colégio? Disponível em: <https://goo.gl/gmHmZG> . Acesso em: 15 maio 2017.

OCUPA PEDRO MACEDO. Sobre as desocupações forçadas. Curitiba, 25 out. 2016. Disponível em: < https://goo.gl/r1FinH>. Acesso em: 12 mar. 2017.

PACHECO, C. S. Ocupar e resistir: as ocupações das escolas públicas como parte do ciclo atual de mobilização juvenil no Brasil. 2018. 271 f. Dissertação (Mestrado em Sociologia) - Universidade Federal do Paraná, Curitiba, 2018.

RUIZ, A. O. Generaciones: movimientos juveniles, políticas de la identidad y disputas por la visibilidad en el Chile neoliberal. Ciudad Autónoma de Buenos Aires: Clacso, 2014.

SANTOS, M. O retorno do território. In: OSAL. Observatório social de América Latina. Buenos Aires: Clacso, 2005. p. 251-261.

SCHMIDT, M. A.; DIVARGIM, T.; SOBANSKI, A. \#OcupaPR2016: memórias de jovens estudantes. Curitiba: W.A., 2016.

TARROW, S. Ciclos de acción colectiva: entre los momentos de locura y el repertorio de contestación. In: TRAUGOTT, M. (Org.). Protesta social: repertorios y ciclos de la acción colectiva. Barcelona: Hacer, 2002. p. 99-129. 
TAYLOR, D. O arquivo e o repertório: performance e memória cultural nas Américas. Tradução de E. L. Reis. Belo Horizonte: UFMG, 2013.

THOMPSON, E. O termo ausente: experiência. In: THOMPSON, E. A miséria da teoria ou um planetário de erros: uma crítica ao pensamento de Althusser. Rio de Janeiro: Zahar, 1981. p. 180-200.

VIDRIO, S. G. El papel de las emociones en la conformación y consolidación de las redes y movimientos sociales. In: ARIZA, M. (Org.). Emociones, afectos y sociología: diálogos desde la investigación social y la interdisciplina. México: Instituto de Investigaciones Sociales (UNAM), 2016. p. 399-440.

WACQUANT, L. Corpo e alma: notas etnográficas de um aprendiz de boxe. Relume Dumará, Rio de Janeiro, v. 8, n. 2, p. 220-222, 2002. DOI: https://doi.org/10.1590/s0104$\underline{93132002000200015}$

Recebido em 31/03/2019

Versão corrigida recebida em 18/05/2019

Aceito em 21/05/2019

Publicado online em 01/06/2019 